\title{
Mechanical Interlocking between Porous Electrospun Polystyrene Fibers and an Epoxy Matrix
}

\author{
Mustafa M. Demir, ${ }^{\dagger}$ Nesrin Horzum, ${ }^{\ddagger}$ Alper Taşdemirci, ${ }^{\S}$ Kivanç Turan, ${ }^{\S}$ and Mustafa Güden*,§ \\ ${ }^{\dagger}$ Department of Materials Science and Engineering, and ${ }^{\S}$ Mechanical Engineering, İzmir Institute of Technology, Urla, 35430 İzmir, \\ Turkey \\ ${ }^{\ddagger}$ Department of Engineering Sciences, İzmir Kâtip Çelebi University, Çiğli, 35620 İzmir, Turkey
}

Supporting Information

\begin{abstract}
An epoxy matrix filled with nonwoven mats of porous polystyrene (PS) fibers processed by an electrospinning was compression tested at quasi-static $\left(1 \times 10^{-3} \mathrm{~s}^{-1}\right)$ and high strain $\left(315 \mathrm{~s}^{-1}\right)$ rates. The electrospun PS fibers with a diameter between 6 and $9 \mu \mathrm{m}$, accommodated spherical pores on the surface with the sizes ranging from 0.1 to $0.2 \mu \mathrm{m}$. The filling epoxy matrix with $0.2 \mathrm{wt} \%$ PS fibers increased the compressive elastic modulus and compressive strength over those of neat epoxy resin. The microscopic observations indicated that the surface pores facilitated the resin intrusions into the fiber, enhancing the interlocking between resin and fibers, and increased the deformation energy expenditure of the polymer matrix.
\end{abstract}

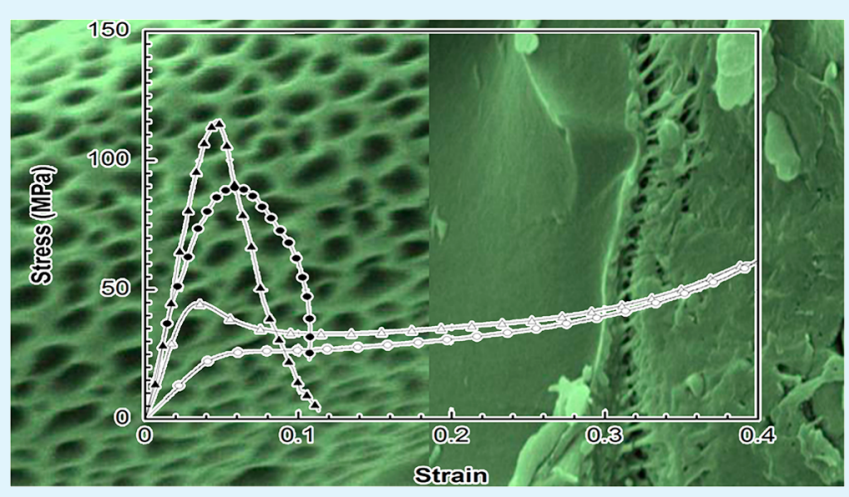

KEYWORDS: electrospinning, epoxy matrix, composite, compression, high strain rate

$\mathrm{T}$ he fields of application for fiber-reinforced polymer composites (FRPCs) over the last few decades have widened in aerospace, defense, transportation, and automotive industries. ${ }^{1}$ The strength of FRPCs is derived to a large extent from the inclusion of $10-100 \mu \mathrm{m}$ size strong fibers or fiber networks into complaint polymer matrices. The effectiveness of fibers in enhancing the mechanical properties of FRPCs is also affected by the interface between fibers and the matrix. The recent rapid progress and pace taken in the field of nanotechnology has resulted in novel techniques of processing submicron and nanometer size fibers of a relatively high surface area. ${ }^{2}$ The high fiber surface area associated with small fiber size causes nanometer-scale interlocking between the fiber and the matrix, enhancing the load transfer from the fiber to the matrix, which requires additional energy expenditure to deform the polymer matrix. $^{3-7}$

Ultrathin fibers may conveniently be processed by electrospinning. ${ }^{8}$ In electrospinning, a charged jet is ejected from a droplet of a solution through grounded collector under a high electrical field when the electrical force overcomes the surface tension of the droplet. By altering the electrospinning parameters including the spinning atmosphere, ${ }^{9}$ solvent composition, ${ }^{10}$ and calcination, ${ }^{11}$ randomly oriented mechanically integrated nonwoven fibrous polymer mats with tunable fiber sizes and surfaces, internal porosities, and pore sizes are processed.

There has recently been a rise in interest in exploring electrospun fibrous mats as reinforcement in FRPCs as these mats have the potentials of efficient stress transfer to matrix, high strength to weight ratio, and excellent multifunctional properties. The significant improvement in the mechanical response of FRPCs was also attributed to the nature of the interfacial bonding between nanofibers and polymeric matrices. ${ }^{12-15}$ The cross-linked polystyrene-co-glycidyl methacrylate $\mathrm{P}($ St-co-GMA)/ethylenediamine (EDA) nanofiber filled epoxy matrix showed 2.5 times higher storage modulus than $\mathrm{P}$ (St-co-GMA) nanofiber filled epoxy matrix, proving the substantial effect of cross-linking between the nanofibers and polymer matrix on the mechanical properties. ${ }^{16}$

The experimental studies on the electrospun fiber reinforced polymeric composites were previously reported in the literature, ${ }^{17-19}$ but there have been no experimental investigations, to the authors' present knowledge, reported on the mechanical properties of porous ultrathin fiber reinforced polymer matrices. With the adjustment of humidity level ${ }^{20}$ and the use of a suitable solvent type, ${ }^{21}$ the extent of the formation of the interior and surface pores of the fibers is monitored in the electrospinning of PS; therefore, the PS may be considered as a model material for the systematical investigation of the effect of the process variables on the fiber properties in the electrospinning process. The aim of the present study is to examine the effect of incorporation of porous electrospun PS fibers on the quasi-static and dynamic compression behavior of a polymer matrix. This study also aims to provide, for the first

Received: October 14, 2014

Accepted: December 8, 2014

Published: December 8, 2014 
time, high strain rate deformation experimental data on such porous ultrathin fiber-reinforced polymer matrices.

PS chips (Aldrich) were dissolved in tetrahydrofuran (THF) (Sigma-Aldrich) to prepare solutions between 10 and $30 \mathrm{wt} \%$ of solid contents. Then, the solution was fed into a $20 \mathrm{~mL}$ syringe with a stainless steel needle and a potential difference of $2.5 \mathrm{kV} \mathrm{cm}^{-1}$ (the applied voltage, $15 \mathrm{kV}$, the tip-to-collector, 6 $\mathrm{cm}$ ) was applied to the solution by means of a Gamma Voltage ES-40P-20 W power supply. The flow rate of the solution varied between 3 and $5 \mathrm{~mL} \mathrm{~h}^{-1}$, which was controlled using a syringe pump (LION WZ-50C6). The humidity level in the spinning environment was 55\%. Microscopic analysis was performed using a scanning electron microscope (SEM), FEI Quanta 250. The average fiber diameter was determined using the ImageJ Software. The experimental steps for the fabrication of epoxy/PS fiber composite are shown in Figure 1. The fiber

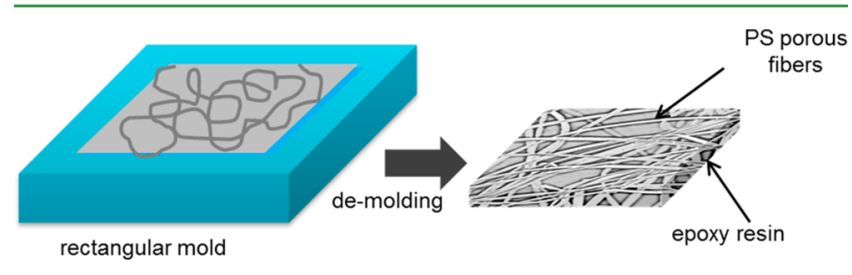

Figure 1. Flowchart of processing epoxy/PS fiber composite.

mat was first inserted into a $18 \times 18 \times 21 \mathrm{~mm}^{3}$ size silicon mold and then Super Selva Epoxy 400 A resin-2.5 wt \% hardener mixture was impregnated to the fiber mat by a mechanical mixing. The resin-fiber mixture was kept in a mold inside a closed box with a vacuum outlet from the top of the box. The vacuum $(1 \mathrm{~Pa})$ is applied to remove the air bubbles. Then, the mixture was allowed to wait in the mold at room temperature for $24 \mathrm{~h}$. The filled epoxy matrix contained approximately 0.2 wt \% of PS fibers. After a demolding step, the front and back faces of the epoxy composites were grinded to achieve parallel surfaces. For comparison, neat resin samples were also prepared using a similar processing route. Quasi-static compression tests were performed in a Shimadzu AG-X universal test machine at the strain rate of $10^{-3} \mathrm{~s}^{-1}$. High strain rate testing was performed in a compression type Split Hopkinson Bar (SHPB) setup. The details of the used SHPB setup and the data reductions are provided elsewhere. ${ }^{22}$ The bars of SHPB were made from VASCOMAX C-350 high strength maraging steel. In a typical SHPB test, a gas gun fires the striker bar to the end of the incident bar (Figure 2a). This creates a compression wave on the incident bar which moves to the specimen bar interface, where it is partly reflected as a tension wave to the incident bar and partly as a compressive wave on the transmitted bar. The incident, reflected and transmitted waves are measured by means of strain gages mounted on the incident and transmitter bars (Figure 2b). The strain rate $(\dot{\varepsilon})$, strain $(\varepsilon)$, and stress $(\sigma)$ in the specimen in $\mathrm{SHPB}$ testing are calculated using the following equations based on one-dimensional wave propagation in long bars

$$
\begin{aligned}
& \dot{\varepsilon}(t)=\frac{-2 C_{\mathrm{b}}}{L_{\mathrm{s}}} \varepsilon_{\mathrm{r}}(t) \\
& \varepsilon(t)=\frac{-2 C_{\mathrm{b}}}{L_{\mathrm{s}}} \int_{0}^{t} \varepsilon_{\mathrm{r}}(t) \mathrm{d} t \\
& \sigma(t)=\frac{E_{\mathrm{b}} A_{\mathrm{b}}}{A_{\mathrm{s}}} \varepsilon_{\mathrm{t}}(t)
\end{aligned}
$$

where $C_{\mathrm{b}}$ and $E_{\mathrm{b}}$ are the elastic wave velocity and elastic modulus of the bar, $L_{\mathrm{s}}$ is the sample gage length, $A_{\mathrm{s}}$ and $A_{\mathrm{b}}$ are

(a)

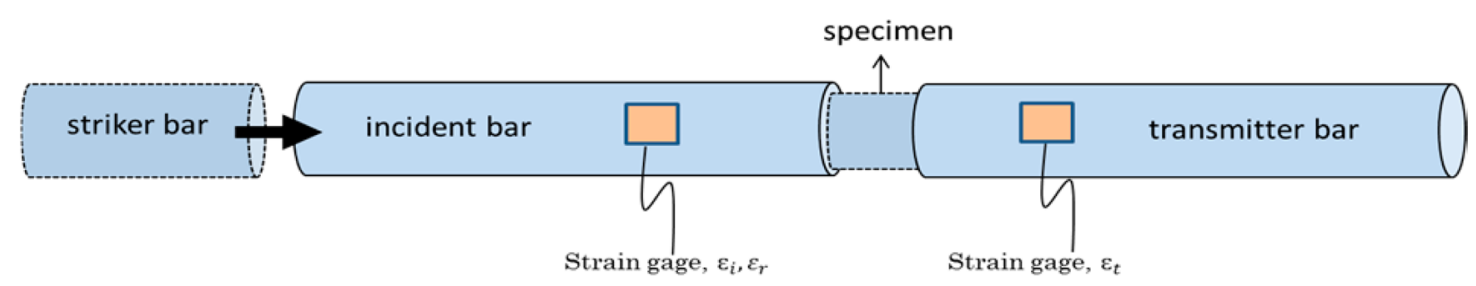

(b)

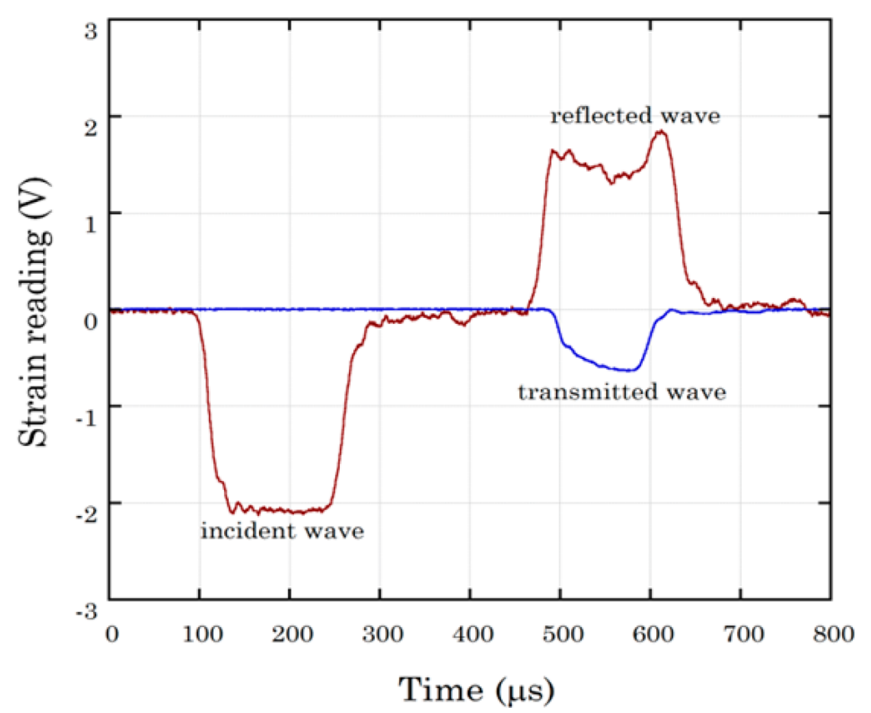

Figure 2. Schematic of (a) SHPB testing and (b) typical strain reading from a SHPB testing. 


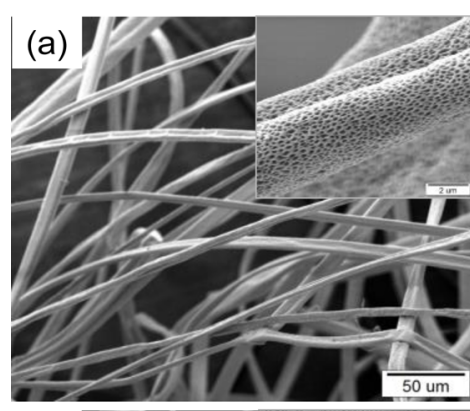

(b)

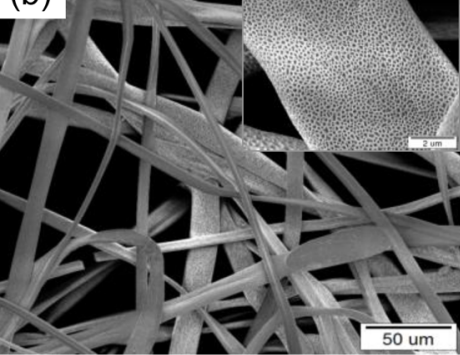

(c)

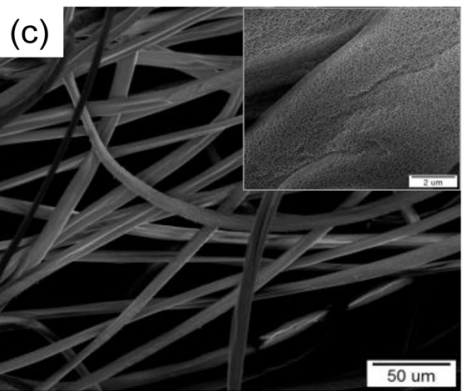

(d)

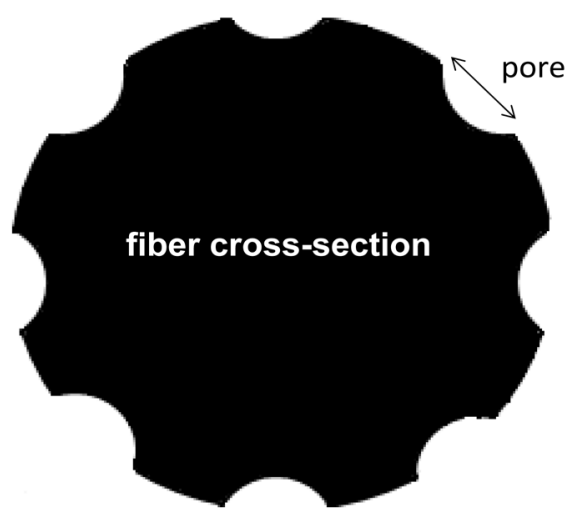

(e)

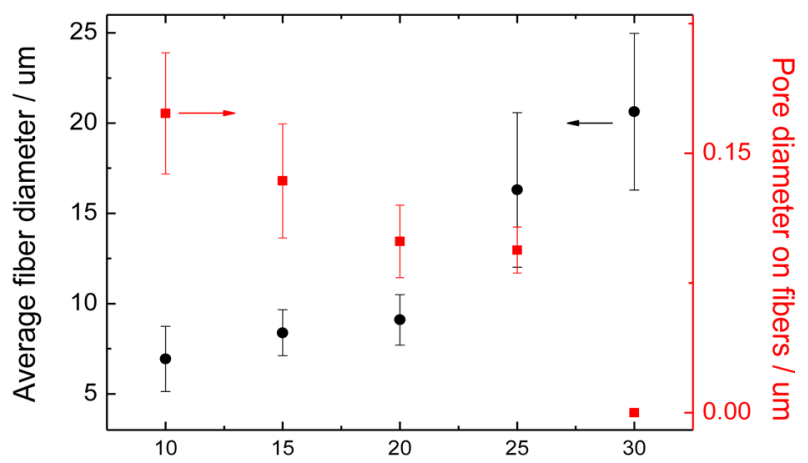

Solid content in polymer solution / wt \%

Figure 3. SEM micrographs of PS fibers obtained from THF solutions at different weight fractions under $55 \%$ RH (a) 0.10 , (b) 0.15 , (c) 0.20 (insets are higher magnifications of PS fiber surfaces showing the pores). (d) Schematic representation of the cross-sectional view of the PS fiber electrospun from $10 \mathrm{wt} \%$ THF solution. (e) Average fiber and pore diameter as a function of polymer concentration.

the sample and bar cross-sectional areas, respectively. $\varepsilon_{\mathrm{r}}$ and $\varepsilon_{\mathrm{t}}$ are the reflected and transmitted strains measured from strain gages on the bar, respectively.

There are two reasons why the compression test was selected over the tension test. First, in tension test, the material failure is initiated at the weakest link, leading to rapid failure of the sample, obscuring the reveal of fiber interlocking under microscope. The weakest link might even be arisen from the geometrical features of the tensile test specimen. While, in compression test, the test results is less affected by the geometry; only the friction between compression test platens and sample surface may result in artificial results. Second, the alignment of the sample in tension test is more difficult than in compression test. Since the main aim of the current study is to present the effect of strengthening mechanisms on the dynamic mechanical behavior, not to characterize the mechanical behavior of the composite, the compression test was preferred.

Figure $3 a-c$ shows the SEM micrographs of the electrospun porous fibers using three different PS solution concentrations. In the insets of the same micrographs, the fiber surface morphologies are shown at higher magnifications. The ribbonshaped fibers accommodate surface pores on a nanometer scale, resulting not only from the humid environment but also from the use of a volatile solvent. The pores are noted to be homogeneously distributed over the fiber surfaces, having a nearly round-shape with nanosized diameter. The pore formation, which only occurs on the fiber surface and shown schematically in Figure 3d, is consistent with what is set out in the literature. ${ }^{11}$ The dependence of average fiber diameter (AFD) and pore diameter on the PS weight fraction is demonstrated in Figure 3e. The increase of solution concentration from 0.1 to 0.2 increases the AFD from 7 to $20( \pm 3) \mu \mathrm{m}$, and decreases the pore diameter from 170 to $100( \pm 30) \mathrm{nm}$. THF has higher vapor pressure than that of water so that it has high evaporation rate. Evaporation causes cooling on the surface of the PS fibers and therefore the formation of breath figures. The thermally induced phase separation may be active during the structural development of the fibers in the electrospinning process. ${ }^{21,23,24}$

The quasi-static $\left(1 \times 10^{-3} \mathrm{~s}^{-1}\right)$ and high strain rate $\left(315 \mathrm{~s}^{-1}\right)$ compression stress-strain curves of PS fiber-reinforced and neat epoxy resin are shown in Figure 4. The strain rate and the addition of the PS fibers increase both the elastic modulus and compression strength of the epoxy matrix. With the addition of 0.2 wt \% PS fibers, the quasi-static compressive elastic modulus of neat epoxy increase from 0.6 to $1.8 \mathrm{GPa}$ and the compressive strength from 26 to $44 \mathrm{MPa}$. When the strain rate increases to $315 \mathrm{~s}^{-1}$, the compressive strength increases to $90 \mathrm{MPa}$ in neat epoxy and to $115 \mathrm{MPa}$ in a filled epoxy. The increased compressive strength of the filled epoxy at the high strain rate is a key outcome of the strain rate sensitive compressive strength of the matrix, while the increased strength of filled epoxy over neat epoxy resin at the quasi-static strain rate is mainly due to PS fiber addition. 


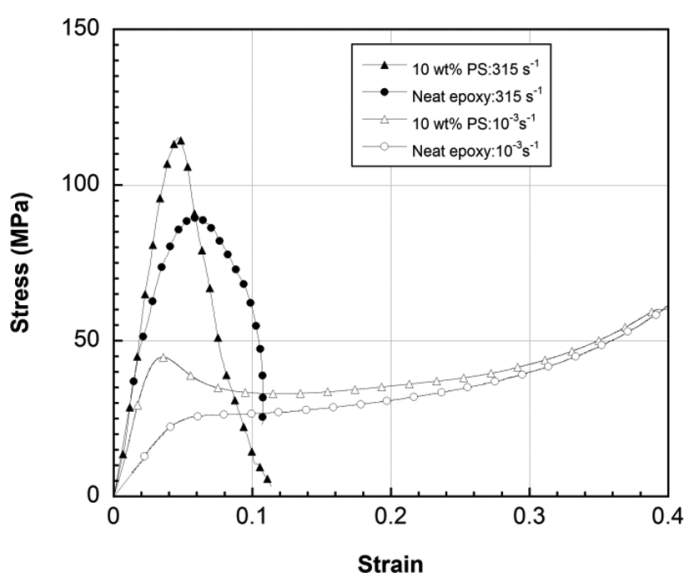

Figure 4. Compression stress-strain curves of $10 \mathrm{wt} \%$ PS fiber reinforced and neat epoxy resin at the quasi-static and high strain rate.

Both neat and filled epoxy samples fractured in the high strain rate tests at relatively low strain values. The increased strength at high strain rates in glassy polymers usually results in reduced ductility. ${ }^{25}$ This effect is more pronounced in the filled epoxy.

The filled and neat epoxy samples tested at high strain rate were found to be not suitable for the microscopic observations as the fractured pieces of the epoxy samples were squashed between the SHPB test bars. Therefore, only the quasi-statically tested epoxy pieces were examined microscopically. Figure 5a$\mathrm{d}$ show the SEM micrographs of quasi-statically tested filled epoxy samples' fracture surfaces. The fracture surface seen in Figure 5a is composed of debonded/separated fiber network and relatively flat fracture areas of the matrix. It is noted in the same figure that the pores on the fiber surfaces had been sheltered by the matrix. A close inspection of the fracture surface reveals the remnants of the matrix ligaments at the separated fiber-matrix interface (Figure $5 b$ ). A strong interlocking in the nanometer-scale between the fiber and the matrix is further evident in Figure 5c, d, in which the stretched matrix ligaments in a region near the fiber-matrix interface are clearly seen. The interlocking occurs as a result of resin penetration/ intrusions to the porosities on the fiber surface. In addition to high fiber surface area, ${ }^{3}$ the resin intrusions to fibers further improve the interlocking between the fiber and the matrix. The strong interlocking is believed to have improved the load transfer from matrix to fiber and hence requires additional energy expenditure of the polymer matrix deformation.

One can consider testing a control study using smooth PS fibers with the same thickness for comparison of our current results. It has to be noted that the surface of the fibers gets smooth when the concentration of electrospinning solution increases; simultaneously, the diameter of fibers increases. Thus, the comparison of the mechanical properties of epoxy composites prepared by porous thin and smooth-surface thick fibers becomes impossible. The preparation of thin and smooth electrospun fibers can only be obtained by changing solvent type and/or instrumental parameters such as applied voltage and spinning distance.

In summary, the micrometer-size porous PS fibers prepared by electrospinning of THF solution with the nano size surface porosities were used to fill an epoxy matrix with a weight percent of 0.2. The compressive elastic modulus and strength increased with the addition of PS fibers and with increasing strain rate. The increased compressive strength of the filled epoxy was attributed to the enhanced interlocking between the resin and fibers by the intrusions of the resin into pores on the fibers. The excessive deformation of the matrix at the interface led to extra energy expenditure to deform the fiber reinforced polymer composite. A detailed study dealing with the effect of PS fiber amount, thickness of the fibers, and the size of pores
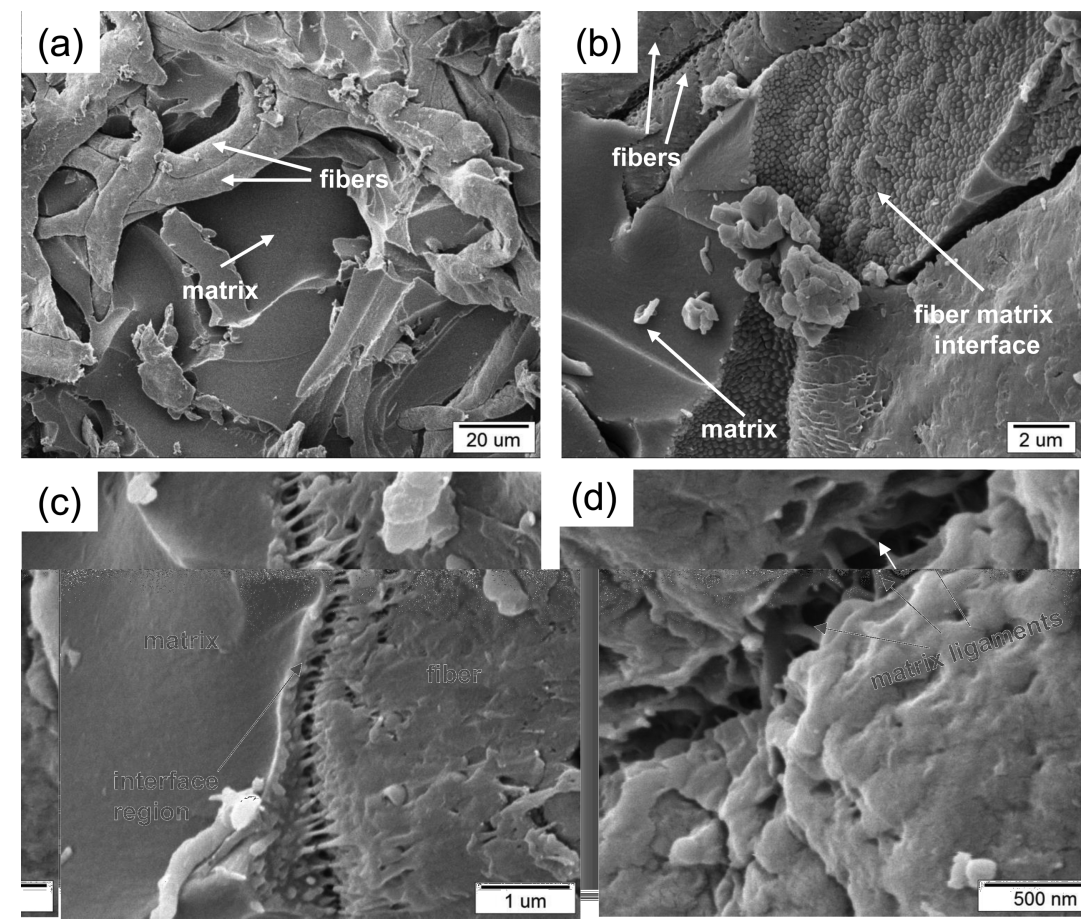

Figure 5. SEM micrographs of quasi-static compression tested $10 \mathrm{wt} \%$ PS fiber reinforced epoxy showing (a) the fiber network on the fracture surface, (b) the ligaments of the fiber debonding, (c) the fiber-matrix interface, and (d) matrix ligaments at the fiber matrix interface. 
on the mechanical properties of the resulting epoxy composites is underway.

\section{ASSOCIATED CONTENT}

\section{S Supporting Information}

Experimental details. This material is available free of charge via the Internet at http://pubs.acs.org.

\section{AUTHOR INFORMATION}

\section{Corresponding Author}

*E-mail: mustafaguden@iyte.edu.tr.

\section{Notes}

The authors declare no competing financial interest.

\section{ACKNOWLEDGMENTS}

The authors thank Mr. T. Baffou, Mr. A. Altık, and Mr. H. Bilir for their help in the experiments.

\section{REFERENCES}

(1) Gibson, R. F. A Review of Recent Research on Mechanics of Multifunctional Composite Materials and Structures. Compos. Struct. 2010, 92, 2793-2810.

(2) Doshi, J.; Reneker, D. H. Electrospinning Process and Applications of Electrospun Fibers. J. Electrost. 1995, 35, 151-160.

(3) Liao, L.; Ren, Y.; Xiao, T. Polymer Nanocomposites; Mai, Y. W., Yu, Z. Z., Eds.; Woodhead Publishing: Cambridge, U.K., 2006; pp $330-356$.

(4) Herrera-Franco, P. J.; Valadez-Gonzalez, A. A study of the mechanical properties of short natural-fiber reinforced composites. Compos. Pt. B-Eng. 2005, 36, 597-608.

(5) Joseph, S.; Sreekala, M. S.; Oommen, Z.; Koshy, P.; Thomas, S. A comparison of the mechanical properties of phenol formaldehyde composites reinforced with banana fibres and glass fibres. Compos. Sci. Technol. 2002, 62, 1857-1868.

(6) Rong, M. Z.; Zhang, M. Q.; Liu, Y.; Yang, G. C.; Zeng, H. M. The effect of fiber treatment on the mechanical properties of unidirectional sisal-reinforced epoxy composites. Compos. Sci. Technol. 2001, 61, 1437-1447.

(7) Valadez-Gonzalez, A.; Cervantes-Uc, J. M.; Olayo, R.; HerreraFranco, P. J. Effect of fiber surface treatment on the fiber-matrix bond strength of natural fiber reinforced composites. Compos. Pt. B-Eng. 1999, 30, 309-320.

(8) Demir, M. M.; Yilgor, I.; Yilgor, E.; Erman, B. Electrospinning of polyurethane fibers. Polymer 2002, 43, 3303-3309.

(9) McCann, J. T.; Marquez, M.; Xia, Y. N. Highly Porous Fibers by Electrospinning into a Cryogenic Liquid. J. Am. Chem. Soc. 2006, 128, $1436-1437$.

(10) Han, S. O.; Youk, J. H.; Min, K. D.; Kang, Y. O.; Park, W. H. Electrospinning of Cellulose Acetate Nanofibers Using a Mixed Solvent of Acetic acid/Water: Effects of Solvent Composition on the Fiber Diameter. Mater. Lett. 2008, 62, 759-762.

(11) McCann, J. T.; Li, D.; Xia, Y. N. Electrospinning of Nanofibers with Core-sheath, Hollow, or Porous Structures. J. Mater. Chem. 2005, $15,735-738$.

(12) Dong, Y.; Mosaval, T.; Haroosh, H. J.; Umer, R.; Takagi, H.; Lau, K.-T. The Potential Use of Electrospun Polylactic Acid Nanofibers as Alternative Reinforcements in an Epoxy Composite System. J. Polym. Sci., Part B: Polym. Phys. 2014, 52, 618-623.

(13) Fong, H. Electrospun Nylon 6 Nanofiber Reinforced BISGMA/TEGDMA Dental Restorative Composite Resins. Polymer 2004, 45, 2427-2432.

(14) Liao, H.; Wu, Y.; Wu, M.; Zhan, X.; Liu, H. Aligned Electrospun Cellulose Fibers Reinforced Epoxy Resin Composite Films with High Visible Light Transmittance. Cellulose 2012, 19, 111-119.

(15) Oh, H. J.; Han, S. H.; Kim, H. Y.; Kim, S. S. The Influence of the Core-shell Structured Meta-aramid/Epoxy Nanofiber Mats on Interfacial Bonding Strength and the Mechanical Properties of Epoxy
Adhesives at Cryogenic Environment. J. Adhes. Sci. Technol. 2014, 28, 950-962.

(16) Ozden, E.; Menceloglu, Y. Z.; Papila, M. Engineering Chemistry of Electrospun Nanofibers and Interfaces in Nanocomposites for Superior Mechanical Properties. ACS Appl. Mater. Interfaces 2010, 2, $1788-1793$.

(17) Kim, J. S.; Reneker, D. H. Mechanical Properties of Composites Using Ultrafine Electrospun Fibers. Polym. Compos. 1999, 20, 124131.

(18) Bergshoef, M. M.; Vancso, G. J. Transparent Nanocomposites with Ultrathin, Electrospun Nylon-4,6 Fiber Reinforcement. Adv. Mater. 1999, 11, 1362-1365.

(19) Jiang, S. H.; Hou, H. Q.; Greiner, A.; Agarwal, S. Tough and Transparent Nylon-6 Electrospun Nanofiber Reinforced MelamineFormaldehyde Composites. ACS Appl. Mater. Interfaces 2012, 4, 2597-2603.

(20) Pai, C. L.; Boyce, M. C.; Rutledge, G. C. Morphology of Porous and Wrinkled Fibers of Polystyrene Electrospun from Dimethylformamide. Macromolecules 2009, 42, 2102-2114.

(21) Megelski, S.; Stephens, J. S.; Chase, D. B.; Rabolt, J. F. Microand Nanostructured Surface Morphology on Electrospun Polymer Fibers. Macromolecules 2002, 35, 8456-8466.

(22) Tasdemirci, A.; Yuksel, S.; Karsu, D.; Gulturk, E.; Hall, I. W.; Guden, M. Diatom Frustule-filled Epoxy: Experimental and Numerical Study of the Quasi-static and High Strain Rate Compression Behavior. Mater. Sci. Eng., A 2008, 480, 373-382.

(23) Demir, M. M. Investigation on Glassy Skin Formation of Porous Polystyrene Fibers Electrospun from DMF. eXPRESS Polym. Lett. 2010, 4, 2-8.

(24) Srinivasarao, M.; Collings, D.; Philips, A.; Patel, S. Threedimensionally ordered array of air bubbles in a polymer film. Science 2001, 292, 79-83.

(25) Mulliken, A. D.; Boyce, M. C. Mechanics of the Rate-dependent Elastic-plastic Deformation of Glassy Polymers from Low to High Strain Rates. Int. J. Solids Struct. 2006, 43, 1331-1356. 